\title{
O QUE NARRAM AS PROFESSORAS? \\ LIÇÕES E APRENDIZADOS DO ENSINO REMOTO EMERGENCIAL
}

\section{What do Women Teachers Narrate? Lessons and Learnings of Emergency Remote \\ Education}

\author{
Renata Cristina Oliveira Barrichelo Cunha ${ }^{1}$ \\ Priscila Pellegrini de Almeida Bueno ${ }^{2}$ \\ Luciana Haddad Ferreira ${ }^{3}$
}

\begin{abstract}
Resumo: A pandemia da COVID-19 ao longo de 2020 e 2021 exigiu a suspensão das aulas presenciais de todos os níveis de ensino e a solução encontrada para enfrentar o desafio das portas fechadas foi o ensino remoto de emergência. Rádio, televisão, plataformas agregadoras de vídeos e áudios, atividades impressas ou fotocopiadas, mensagens via aplicativo de smartphone e reuniões por chamadas de vídeo, dentre outras propostas, foram recursos empregados para manter o contato com a comunidade educativa em um momento tão crítico. A falta de planejamento e a pouca experiência com o uso de recursos digitais, no entanto, passou a ser uma questão limitadora do trabalho docente. Este estudo objetiva analisar e discutir o tema a partir da análise das narrativas de 12 professoras, escritas no período de pandemia, sobre as experiências com o ensino remoto emergencial. A pesquisa foi realizada em uma escola da rede privada de ensino que atende alunos da Educação Infantil e séries iniciais do Ensino Fundamental de uma cidade do interior paulista. A discussão baseou-se na análise de conteúdo, evidenciando algumas lições: necessidade de adaptação e flexibilidade com relação à reorganização do trabalho pedagógico; importância do trabalho colaborativo para o enfrentamento dos desafios; e valorização da formação continuada no contexto da escola. Num cenário de provisoriedade que já se estende ao segundo ano da pandemia, as professoras narram aprendizados que podem auxiliar tanto na maneira como se compreendem neste período pandêmico, quanto na docência futura, em novos e outros contextos.
\end{abstract}

Palavras-chave: Ensino remoto. Formação de professores. Narrativas.

Abstract: The COVID-19 pandemic throughout 2020 and 2021 required the suspension of inschool classes at all levels of education and the resolution found to face this challenge was

\footnotetext{
1 Doutora em Educação pela Universidade Estadual de Campinas (Unicamp). Pesquisadora colaboradora do Grupo de Estudos e Pesquisas em Educação Continuada (Gepec/Unicamp). Orcid: https://orcid.org/0000-0002-5662-8062 E-mail: renata_bcunha@yahoo.com.br

2 Mestre em Educação pela Universidade Metodista de Piracicaba (Unimep). Diretora Pedagógica da Maple Bear Itapetininga. Orcid: https://orcid.org/0000-0003-1255-3107 E-mail: pellegrinipriscila@ gmail.com

3 Doutora em Educação pela Universidade Estadual de Campinas (Unicamp). Professora permanente do Programa de Pós-Graduação em Educação da Universidade Metodista de Piracicaba (Unimep) e professora contratada do Departamento de Educação da Universidade Federal do Rio de Janeiro (UFRJ)Pesquisadora colaboradora do Grupo de Estudos e Pesquisas em Educação Continuada (Gepec/Unicamp). Orcid: https://orcid.org/0000-00028440-7347 E-mail: haddad.nana@gmail.com
} 
emergency remote education. Radio, television, video and audio aggregation platforms, printed or photocopied activities, messages via smartphone app and video call meetings, among other proposals, were resources used to maintain contact with the educational community at such a critical moment. The absence of planning and insufficient experience of using digital resources, however, became a limiting issue to teach. This research aims to analyze and discuss this topic from the review of the narratives of 12 teachers, written during the pandemic period, about the experiences with emergency remote education. The research was carried out in a basic education school in the private education network that serves students from Early Childhood Education and Elementary School in a city in the interior of São Paulo.. The discussion was based on content analysis, highlighting some lessons: need for adaptation and flexibility regarding the reorganization of the pedagogical work; importance of collaborative work to face challenges; and valuing continuing education in the school context. In a temporary scenario that already extends into the second year of the pandemic, the teachers narrate learnings that can help both in the way they understand themselves in this pandemic period, as well as in future teaching, in new and other contexts.

Keywords: Remote education. Training teachers. Narratives.

\section{Introdução}

A escrita deste texto é realizada no decorrer do segundo ano da pandemia de COVID19, vivenciada globalmente desde 2019. No Brasil, mesmo diante da ausência de um plano nacional rigoroso, fundamentado e assertivo que objetivasse minimizar o contágio e evitar casos graves e mortes pela doença (SILVA, 2020), estados e municípios inicialmente determinaram a suspensão de atividades coletivas e com grande número de pessoas envolvidas. Neste contexto, as aulas presenciais de todos os níveis de ensino, tanto da rede pública quanto privada, foram suspensas. Diante da gravidade da situação vivenciada, considerando a ausência de informações que possibilitassem compreender a duração exata deste período de isolamento, ainda no início de 2020 a solução encontrada para enfrentar o desafio das escolas com portas fechadas foi o "ensino remoto de emergência", considerado naquela ocasião como um recurso emergencial, temporário e de curta duração, como define Verdasca (2021).

$\mathrm{O}$ ensino remoto de emergência foi pensado e desenvolvido de maneira diferente em cada localidade do país, a depender da rede de ensino, dos recursos e das políticas traçadas pelas secretarias de Educação. Estudos como o de Macedo (2021) apresentam iniciativas de ensino remoto por rádio, televisão, plataformas agregadoras de vídeos e áudios, atividades impressas ou fotocopiadas, mensagens via aplicativo de smartphone e reuniões por chamadas de vídeo, dentre outras propostas. Se num primeiro momento a mudança do presencial para o virtual foi a alternativa encontrada para a não interrupção do processo de ensino (WEYH; NEHRING, 2020) e, sobretudo, uma tentativa de manter vínculos afetivos e contato direto com a comunidade educativa em um momento tão crítico, com o passar dos meses as orientações de progressivo retorno ao modelo presencial vieram acompanhadas da ideia de manutenção das atividades remotas como possibilidade de escalonamento de alunos e redução do número de crianças no espaço escolar. O que parecia passageiro ganha outros contornos.

O momento atualmente vivenciado é de disputa entre narrativas sobre a pandemia, que abarcam em suas tramas diferentes entendimentos sobre o papel e o lugar da instituição escolar, neste contexto. Ao passo que parcela da sociedade e de seus dirigentes defendem o regresso ao ambiente da escola em sua suposta quase normalidade, após algum (ainda não expressivo) 


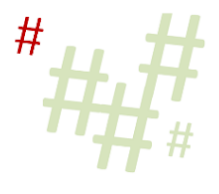

avanço na campanha de vacinação no país, outros discutem perversamente a relação entre economia e saúde, considerando números de mortes aceitáveis. Em meio a essas e outras narrativas já conhecidas, professores e pesquisadores do campo da educação observam a dificuldade de planejar um retorno seguro ao ensino presencial, num país onde a epidemia não está controlada e figuras públicas desencorajam o cumprimento de protocolos e deliberadamente promovem a exposição e aglomeração da população (SILVA, 2020).

Diante deste entrave, com aberturas e suspensões de aulas acontecendo alternadamente, a depender dos indicadores de contágio e ocupação de leitos em hospitais, o ensino remoto emergencial permanece na pauta e na prática docente cotidiana, se misturando com certa naturalidade ao debate sobre o retorno, pois ainda há a necessidade de promover rodízio de turmas de alunos, assim como é assegurada, para aquelas pessoas que ainda possam se apresentar sintomáticas, doentes ou em situação de risco, a possibilidade de realizar atividades à distância.

Compreendendo que o ensino remoto, tomado como emergencial, já se realiza pelo segundo ano e entendendo que a crise política e sanitária vivida não oferece, ainda, perspectiva de retorno a uma situação de ensino exclusivamente presencial, verifica-se a necessidade de tomar como objeto de estudo as experiências docentes com o ensino remoto emergencial, na busca por ensinamentos e lições que possam auxiliar as professoras no enfrentamento do momento vivido.

É sabido que a urgência do isolamento social não permitiu a preparação, o planejamento e a organização das professoras para que suas atividades profissionais fossem adequadamente desenvolvidas em formato remoto utilizando, muitas vezes, a metodologia de tentativa e erro. Ainda, de acordo com Peres (2020), a falta de preparo dos docentes foi em muitas situações agravada pela precariedade dos recursos disponíveis para o desenvolvimento das suas aulas, uma vez que computador, câmera, smartphone e bom acesso à internet, dentre outros recursos, nunca foram exigências para o desenvolvimento do trabalho pedagógico escolar. Da mesma forma, alunos, familiares e demais trabalhadores da equipe pedagógica precisaram aprender as especificidades desse formato de ensino durante o próprio processo, sem também possuir recursos e instrumentos adequados para este formato de ensino.

Ferreira e Barbosa (2020) destacam as novidades impostas durante a condução desse novo modelo: falta de familiaridade com a tecnologia, exigência de mais dedicação, pressão para atender a demandas e expectativas, sobrecarga de trabalho, ausência de horário e espaço próprios para o trabalho. Segundo as autoras, os docentes se viram despreparados para lidar com a situação do ensino remoto e, ao mesmo tempo, buscaram alternativas para tentar manter seus compromissos com os alunos e instituições, mesmo diante da insegurança, medo, estresse e tensão que relataram vivenciar. Tal situação agravou e escancarou problemas nada novos, relacionados às condições de ensino e de trabalho vivenciadas há tempos no país.

A falta de planejamento e a pouca experiência com o uso de recursos digitais passou a ser uma questão limitadora da criação pedagógica docente. Após uma primeira reação talvez entusiasmada ou otimista, que caracterizou uma prática improvisada, desgastante e, aparentemente, pouco efetiva (SALDANHA, 2020; RONDINI; PEDRO; DUARTE, 2020), as professoras, muitas vezes, passam a ministrar aulas apoiados na própria fala e na exclusiva transmissão de conteúdos, buscando mecanismos de controle da atenção dos alunos, que silenciam e se fecham em suas telas, em atitude de meros consumidores de informação.

Em outras situações, docentes se viram impelidos a adotar um comportamento de influenciador digital ou youtuber, assim como apontado por Santos, Lima e Sousa (2020), assumindo atitudes, jargões e posturas que chamassem a atenção de seus alunos e assegurassem 
uma "curtida" no conteúdo produzido. Por isso, somadas às dificuldades pessoais (de atravessar a pandemia) e profissionais (de vivenciar a mudança do ensino presencial para o remoto sem o devido preparo e recursos), é ainda preocupação da professora lidar com a própria exposição nas redes sociais.

Neste contexto, professoras têm sido colocados em uma situação difícil de conciliar demandas que não eram suas e, consequentemente, com pouca condição de exercer sua função primordial, que é a de organizar situações sociais potentes para o aprendizado e desenvolver o ensino de modo a possibilitar experiências formativas emancipadoras.

Considerando as situações vividas pelas próprias professoras neste período, reafirmando a importância de ouvir o que os profissionais da área da Educação têm a dizer a respeito de seu trabalho, este estudo objetiva analisar e discutir o tema a partir da análise de narrativas, escritas no período de pandemia, sobre as experiências com o ensino remoto emergencial. As narrativas docentes anunciam/denunciam questões sobre a formação docente e a organização do trabalho pedagógico que podem suscitar importantes reflexões sobre o papel da escola e da formação continuada no contexto da pandemia e do ensino remoto. São destacados, assim, os aprendizados possíveis a partir desse diálogo.

\section{Encaminhamentos metodológicos}

A pesquisa, de natureza qualitativa, parte de uma realidade e uma situação social específica e se propõe a analisar aspectos particulares do contexto educacional. A partir da realidade investigada são analisadas ações e elaboradas reflexões a fim de compreender suas relações, intenções e significados (MINAYO, 1993).

Como apontado por Lima, Geraldi, C. e Geraldi, J. (2015), as ciências humanas devem ser compreendidas como ciências do singular que permitem ao pesquisador extrair lições das experiências que podem iluminar o passado e, ao mesmo tempo, indicar caminhos de futuro. Nesse processo, o pesquisador pode traduzir princípios que, mesmo que circunstanciados em um determinado espaço-tempo, podem ajudar a pensar em diferentes cenários.

Para responder o objetivo da pesquisa, além de revisão bibliográfica sobre o ensino remoto na pandemia, foi realizado um trabalho de campo em uma escola de educação básica da rede privada de ensino que atende alunos da Educação Infantil e séries iniciais do Ensino Fundamental de uma cidade do interior paulista. A escola atende em torno de 240 alunos e conta com 36 docentes, entre coordenação, professoras regentes, professoras auxiliares e estagiárias ${ }^{4}$.

Os instrumentos selecionados para responder ao objetivo proposto foram narrativas da experiência docente (FREITAS; FIORENTINI, 2007; GALVÃO, 2005; LIMA; GERALDI, C.; GERALDI, J. 2015) solicitadas no contexto do trabalho coletivo remoto ${ }^{5}$, em dezembro de 2020, a partir da proposta: "Narre como você tem sentido/percebido esse período de pandemia do COVID-19 na sua atuação como docente, as dificuldades que enfrentou (o que descobriu que não sabia), os aprendizados/lições da experiência nesse período e suas necessidades formativas". Assim, as narrativas que antes circulavam oralmente entre o grupo foram registradas por escrito e tomadas para análise neste estudo.

\footnotetext{
4 A pesquisa está vinculada a um projeto financiado pelo Conselho Nacional de Desenvolvimento Científico e Tecnológico - CNPq (Processo no 428099/2018-1) com aprovação do Comitê de Ética (Parecer $n^{\circ}$ 2.917.650).

5 Uma das pesquisadoras atuou como uma das coordenadoras pedagógicas na escola em questão.
} 
Cumpre destacar que a proposta de elaboração de narrativas foi introduzida a partir de esclarecimentos sobre os objetivos da pesquisa, reforçando seu caráter voluntário e seu caráter acadêmico. Posteriormente, o convite foi reforçado por $e$-mail, com solicitação de anuência por meio do Termo de Consentimento Livre e Esclarecido (TCLE). As narrativas foram recebidas até fevereiro de 2021.

A utilização das narrativas como instrumentos de produção de dados é pertinente quando se considera que o ato de narrar, constitutivo do ser humano, permite aos indivíduos atribuir sentido, refletir e interpretar as experiências vividas. Quando distanciados da situação vivida, as professoras, por meio de narrativas, trazem à tona o cotidiano do seu trabalho, seus desafios e capacidade de produzir estratégias de superação; a dimensão do sensível, facilitada pela interpretação das suas condições emocionais; aprendizagens e possibilidades para um vir a ser (SANTOS; LIMA; SOUSA, 2020). Na perspectiva da narrativa ressalta-se a valorização da subjetividade, pois o olhar volta-se para a interpretação e atribuição de significados feitos pelos sujeitos envolvidos. É um instrumento de pesquisa que valoriza o indivíduo, seu modo de ver e pensar sua própria existência. Dessa maneira o pesquisador se aproxima do processo de elaboração e estruturação das reflexões acerca do que foi vivido. Toda essa reflexão, segundo Santos, Lima e Sousa (2020), implica um antes, durante e depois mediado por um discurso explicativo, descritivo, avaliativo e interpretativo, que configura a história daquele que conta.

Das 36 professoras convidadas, 12 professoras se dispuseram a participar da pesquisa, narrando e compartilhando suas angústias, aprendizados e necessidades vivenciadas nesse período $^{6}$. Dentre as participantes, temos mulheres, todas pedagogas, exceto uma licenciada em Educação Física, com idade entre 23 e 35 anos, atuantes na Educação Infantil ou séries iniciais do Ensino Fundamental, com ao menos um ano de trabalho conjunto na escola em questão (exceto uma professora, que integrava o grupo há 5 meses), com mais de três anos de atividade profissional na área, sendo que a professora mais experiente possuía 17 anos de docência. Essa breve caracterização se faz importante para a compreensão de que os textos narrativos, a seguir apresentados, foram produzidos por pessoas que partilham de experiências profissionais comuns, mas as interpretam e vivenciam a partir da singularidade de suas próprias condições de vida e formação.

A análise das narrativas baseou-se na análise de conteúdo, com ênfase na interpretação de sentidos (GOMES, 1993), que envolve organização do material a ser analisado, leitura compreensiva do material, exploração do material (identificação de trechos significativos e estruturas relevantes, definição de unidades de contexto e formulação de eixos temáticos) e síntese interpretativa.

\section{Resultados e discussão}

A partir da leitura e apreciação das 12 narrativas produzidas, foi possível observar a recorrência de termos e situações, apontando para dimensões comuns do trabalho remoto emergencial. Dentre aquilo que era apresentado nas narrativas, questões como a necessidade de adaptar as propostas didáticas para o novo formato, a busca por parcerias e diálogo com outras professoras e a importância da formação continuada estavam presentes na totalidade dos relatos, ora como parte central da trama, ora como contexto ou desdobramento da situação retratada.

\footnotetext{
${ }^{6}$ Considerando que os textos escritos pelas professoras teriam circulação em espaços que não o da sua própria comunidade narradora, todos os nomes das participantes foram substituídos por nomes fictícios, preservando seu anonimato.
} 
As narrativas das professoras apontam sentimentos de ansiedade, incapacidade e exaustão para lidarem com as demandas emocionais e exigências profissionais, como já referido por Dias e Pinto (2020). Tabata e Branca evocam esses sentimentos e revelam seu desgaste e insegurança diante da necessidade de se reorganizarem diante do trabalho remoto:

Tive crises de ansiedade, de choro e, por muitas vezes, quando o dia acabava, eu desligava o computador e dormia até o outro dia (Tabata).

Por muitas vezes me senti mal, incapaz, incompreendida pelos pais, perdida, com vontade de desistir por não saber se o que eu estava fazendo estava, de fato, funcionando, pois não tinha como ter essa proximidade com os alunos (Branca).

O sentimento de exaustão, citado por outras professoras, parece ter sido potencializado pelo trabalho realizado a partir de casa na medida em que tiveram que conciliar demandas profissionais e familiares, com perda de privacidade e prejuízo das condições de trabalho.

\begin{abstract}
Emocionalmente, trabalhar de casa, não ter um horário fixo para começar e terminar, mesclar responder mensagem dos pais dos meus alunos enquanto eu como mãe auxiliava meus dois filhos mais velhos nas suas próprias atividades foi uma carga bem pesada. O trabalho sempre foi "meu espaço" e de certa forma eu perdi essa privacidade (Betina).

Mesmo consciente de todos os privilégios que possuo, não consigo excluir o sentimento de exaustão que me acompanhou durante todo o ano letivo [2020]. A jornada de trabalho aumentou muito e foi difícil dissociar o trabalho e lazer estando em casa o tempo todo, muitas vezes sem saber como organizar toda a demanda [...]. A impressão que tive é que a cada reunião nossa lista de tarefas aumentava e a sensação de "não estar dando conta" era constante. Cheguei a ter crises de pânico após algumas reuniões (Larissa).
\end{abstract}

Barbosa, Cunha e Martins (2019), em pesquisa sobre a jornada docente no ensino presencial, já chamavam a atenção para o fato de que a docência é uma profissão que se estende para além do local de trabalho e invade o espaço e o tempo privados. $\mathrm{O}$ trabalho da professora que sempre foi precedido de muitas horas de planejamento e correção de atividades, além de demandas burocráticas, foi intensificado na pandemia em função da complexidade inerente ao ensino remoto para crianças pequenas.

De acordo com as autoras, é ainda necessário considerar a questão de gênero, pois a docência é uma profissão predominantemente feminina que é afetada pelo trabalho doméstico e o cuidado com os filhos. No caso do ensino remoto, essas esferas da vida de professoras tiveram suas tênues fronteiras ainda mais diluídas, provocando sofrimento emocional.

Santos, Lima e Sousa (2020) e Vieira e Falciano (2020) reforçam que, na pandemia, além das professoras terem que dar conta das tarefas domésticas, maternidade, cuidados de familiares e ensino remoto, suas condições de trabalho foram modificadas e precarizadas significativamente.

No entanto, esses sentimentos de sobrecarga, angústia e insegurança também foram acompanhados por lições e aprendizados com relação à reorganização do trabalho pedagógico. Assim, considerando o objetivo traçado para o estudo, três eixos temáticos emergiram da leitura do material, a saber: a) necessidade de adaptação e flexibilidade; b) importância do trabalho colaborativo; c) formação continuada no contexto da escola. Ressalta-se que os três eixos 
devem ser compreendidos de forma articulada e considerando-se um contexto de grandes dificuldades por parte das professoras.

\title{
3.1 Necessidade de adaptação e flexibilidade
}

Durante os meses de pandemia no ano 2020, me senti extremamente desafiada para me reinventar. Percebi que meu estilo de dar aula não cabia na pequena tela de computador que estava disponível para mim e meus alunos (Carla).

\begin{abstract}
Estar longe de colegas e crianças foi angustiante. Cada hora online era como 5 horas presenciais, e o cenário da pandemia no Brasil não era lá muito otimista, o que me tornava a cada dia mais cansada e pessimista. Percebi que trabalhar de casa e pelo computador realmente não é para mim; que minha formação como Pedagoga não abarcava tudo o que as aulas remotas demandavam; que não sou tão boa com tecnologia como pensava ser; e que a profissão professor é isso: estudar, planejar e se preparar para ser capaz de improvisar (Ana).
\end{abstract}

Assim como Carla e Ana, diversas professoras expressam, em suas narrativas, que a elaboração das suas aulas precisa ser alterada com a mudança para o suporte remoto, pois muitas das práticas antes contempladas não são mais possíveis no modelo virtual. Tais afirmações remetem à dificuldade sentida de tentar manter, minimamente, a proposição de atividades que mobilizem intencionalmente o pensar, fazer e sentir. De acordo com Weyh e Nehring (2020), ao planejar suas aulas, as professoras pressupõem interação corporal, presença física e socialização nos espaços escolares, o que dificilmente acontece nos momentos de aula remota.

Mesmo quando a conexão entre alunos e professora é possibilitada de forma síncrona por vídeo chamada, o tipo de diálogo e troca propiciada é percebido como muito superficial e limitado, seja pelos empecilhos técnicos ou pela pouca disponibilidade dos alunos e famílias, também cansados, assustados e descompromissados com o êxito de um modelo que não foi escolhido ou planejado com/por eles.

As professoras usam muito frequentemente palavras como reconstruir, reinventar, adaptar, flexibilizar ou ajustar, ao se referirem ao próprio trabalho, agora realizado por meio de plataformas digitais. Com isso, deixam explicitada a diferença brutal entre o que se fazia no chão da escola e o que se realiza no contexto do distanciamento social. Expressam a compreensão de que o ensino remoto emergencial pode, em sua melhor possibilidade, oferecer suporte para a transmissão de conteúdos e comunicação entre pessoas, numa relação que talvez traga condições de aprendizado instrucional pontual e circunscrito a certas situações e iniciativas, sem jamais se aproximar das práticas formativas e da relação educativa que se efetiva no espaço escolar.

É curioso, no entanto, que a escrita das professoras, ao mesmo tempo em que remete à consciência de que o ensino remoto emergencial as afasta de uma educação efetiva, reflete a ideia de que é necessário se adaptar a esta nova realidade e corresponder às novas demandas com pouco estranhamento. Parecem incorporar, em certos momentos, o discurso de que é necessário seguir em frente e dar aulas a qualquer custo e em quaisquer condições, como se o êxito no ensino remoto atestasse sua capacidade de se manter produtiva mesmo em situação tão adversa. Isso é percebido no modo como Maria expõe sua experiência:

Tive que me desapegar da "maneira perfeita" de ensinar e reelaborar os objetivos de aprendizagem, visto que teria apenas 30 minutos e três vezes na semana de encontro com as crianças. Sem contar nas horas e horas que foram passadas em cima de 
adaptações dos planejamentos e separação de materiais [...]. É necessário desconstruir para poder construir novamente e de maneira diferente utilizando as mesmas peças (Maria).

Ter que modificar e adaptar toda uma história de docência com as "mesmas peças" parece algo doloroso, violento e complexo, muito embora aqui pareça dito com naturalidade. Nota-se que não houve preparação ou suporte suficiente para tudo que foi vivenciado durante a pandemia. $\mathrm{O}$ trabalho foi intensificado e a aprendizagem sobre o novo modo de ensinar foi forçada e implantada em tempo recorde, definindo um processo de superação das professoras diante de tamanha dificuldade, inclusive emocional, conforme destaca Isis: "Com a constante mudança de estratégias, planejamentos e rotinas, nós professoras nos envolvemos em um turbilhão de aprendizados, emoções e preocupações".

Em contrapartida à ideia de adaptar-se com naturalidade ao "novo normal", em sua narrativa, Maria ainda faz o seguinte registro: "Foram inúmeras perguntas sem respostas e a única certeza é que eu teria que me reinventar e me desdobrar para conseguir passar por esse período turbulento". A professora chama a atenção para uma outra importante dimensão de movimento: diferente da percepção de que o remoto não suporta aquilo que era realizado no presencial, distinto também do entendimento de que a realidade mudou e requer novas atitudes como professora, Maria expressa que sente necessidade de se movimentar como professora para se preservar e atravessar as adversidades vivenciadas, afinal, a necessidade de manter o emprego, a incerteza sobre o futuro e o medo da doença se fazem presentes diariamente.

Seu registro remete à dificuldade, relatada também por outras professoras, de ministrar aulas que são assistidas, analisadas e julgadas não apenas por seus alunos, mas também por seus pais e por outras pessoas que, por vezes, sequer compreendem o contexto das proposições. A adaptação se faz necessária, no entendimento de Maria e de outras professoras, para minimizar sua exposição, evitar atritos e possibilitar estabilidade emocional para prosseguir.

A garantia da continuidade do ensino impôs muitas expectativas a docentes que viram sua competência avaliada pela quantidade de vídeos gravados; seus salários abatidos; que viveram a privação do convívio escolar, cerne do desenvolvimento pedagógico; viveram a incerteza do futuro; o medo da doença; e pressões psicológicas, sociais e morais (FELTRIN; BATISTA, 2020). Como modificar toda uma perspectiva de ensino já conhecida e readaptar seu modo de atuar experienciando tantas angústias, tanta ansiedade e tamanha responsabilidade?

Ainda, não sem identificar e discutir as dificuldades vividas, as professoras também demonstram serem capazes de anunciar aprendizagens do período intenso de mudanças, no que diz respeito à necessidade de se movimentar, adaptar e refletir sobre a própria prática. Sara, em sua escrita narrativa, diz: "Entendi que enquanto docente precisamos estar dispostos a errar, sermos vulneráveis, entender a necessidade do momento e nos adaptar". Palavras como a da professora mostram que a mudança trouxe também a possibilidade de reflexão acerca das práticas e da própria identidade profissional. Se algumas vezes o fazer pedagógico já se direcionava pelas mesmas velhas convicções, sendo orientado quase que mecanicamente por certas estratégias e olhares, o ensino remoto fez ser necessário "desaprender" algumas das certezas teóricas e metodológicas (SANTOS; LIMA; SOUSA, 2020) para então conflitá-las ou reafirmá-las em diálogo com os novos aprendizados.

Nesse período eu descobri muitas ferramentas online como jogos e lições interativas online para complementar os ensinamentos. Essas lições acabaram facilitando as aulas mesmo depois da volta ao presencial. Junto com os alunos acabamos criando várias 
novas tradições para manter o aprendizado divertido. Nesses momentos de readaptação tive que repensar nas maneiras de avaliar meus alunos e medir o aprendizado de cada um. Uma das partes positivas foi conseguir ter um olhar mais profundo de cada aluno e suas necessidades (Carla).

A professora Carla sinaliza que ampliou seu repertório e modificou práticas a partir do contato com as novas ferramentas digitais que teve contato. Também expressa disponibilidade para pensar formas e propostas viáveis para o momento, que possibilitem o diálogo, alguma interação e discussão na relação entre os alunos, a professora e o conhecimento. Martins, Castro e Trancoso (2020) corroboram com tal reflexão, quando discorrem sobre encontrar as saídas criativas para a educação. De acordo com o estudo proposto por eles, as temáticas abordadas pelos docentes no contexto da Covid-19 se destacam pelo compartilhamento de saberes, pela criatividade, pela inventividade e pelo bom uso das interfaces tecnológicas.

\subsection{Importância do trabalho colaborativo}

Dentre os aspectos salientados pelas professoras, aqui apontados para estudos, além da adaptação e disponibilidade para mudança, o trabalho coletivo e compartilhado se mostrou de extrema relevância para que o isolamento social e o ensino remoto emergencial fossem suportados por todas.

A ação docente, no contexto da pandemia, foi sendo modificada e reinventada de acordo com as novas formas de interação com a escola e com as famílias. As professoras, nesse sentido, foram buscando estratégias a fim de reafirmar a sua profissionalidade (SANTOS; LIMA; SOUSA, 2020). Uma dessas estratégias foi o trabalho colaborativo.

O trabalho colaborativo aparece como um eixo importante a ser pontuado e compreendido como fundamental em momentos de crise educacional. Fullan e Hargreaves (2001) defendem o desenvolvimento de um profissionalismo interativo nas escolas e argumentam sobre a necessidade das professoras trabalharem em conjunto instituindo uma cultura colaborativa caracterizada pela ajuda e apoio recíproco e pela reflexão crítica sobre os propósitos e valores subjacentes às suas ações.

A atuação na Educação Básica pressupõe uma formação baseada no trabalho coletivo para compreender e enfrentar as demandas e as questões que a prática docente impõe, principalmente diante dos conflitos (CUNHA; OMETTO; PRADO, 2013). Na interação com os demais colegas, significados são construídos, papéis são constituídos, pontos de vista são compartilhados, modos de compreender o mundo, os alunos, a sala de aula e a própria formação são pensados.

Em muitas das narrativas analisadas, o trabalho colaborativo aparece como uma descoberta dentro de uma profissão tida como solitária. $\mathrm{O}$ isolamento se delineia como uma experiência de certa forma já conhecida pelas professoras, que ao adentrar a própria sala de aula, experimentavam a limitação do desenvolvimento de um trabalho com poucas possibilidades de diálogo e partilha. Ferreira, Prezotto e Terra (2020) argumentam que a solidão também é sentida na falta de políticas públicas educacionais que amparem as professoras e ofereçam condições dignas para desempenhem seu ofício. Essa solidão docente, segundo Fullan e Hargreaves (2001), é ocasionada e reforçada por diversas características da organização e estrutura do modelo escolar vigente, como a arquitetura dos prédios, o horário fragmentado de aulas, o acúmulo e justaposição de tarefas, entre outros aspectos que inviabilizam o encontro e a conversa. 
Quando o ensino remoto é implementado, as professoras se viram ainda mais distantes, afetiva e fisicamente. No entanto, diante dos entraves vivenciados com a migração para o suporte virtual, a parceria, o diálogo e o apoio com/dos demais colegas de profissão pareceu ser essencial para que as dúvidas fossem sanadas e as principais dificuldades enfrentadas. Afinal, diante da falta de infraestrutura, formação e preparo para aquilo que se impôs como nova realidade de forma tão abrupta, foi extremamente necessário compartilhar saberes e buscar/oferecer auxílio umas às outras. A narrativa a seguir evidencia tal sentimento de colaboração:

\begin{abstract}
Enquanto docentes, devemos nos ajudar uns aos outros, dividir experiências e pensar fora da caixa [...]. Percebi que, apesar da profissão docente ser, em seu último estágio, solitária, com cada professor como soberano em sua própria sala, nós dependemos uns dos outros e nos construímos no convívio. Não teria conseguido fazer absolutamente nada, desde os planejamentos até as aulas, sem minhas colegas e equipe gestora. Não teria dado um passo sequer. Em tudo que fiz, tive ajuda. E, em tudo o que pude, ajudei. Mais que as informações da graduação ou dos treinamentos que tivemos, o que mais precisamos nesse ano foi inteligência emocional e trabalho em grupo. Saber lidar com o outro. Dialogar. Construir. Se 2020 me ensinou algo, é que escolhi uma profissão onde jamais serei deixada sozinha. E nunca deixarei ninguém (Ana).
\end{abstract}

A reflexão de Ana reforça o que Damiani (2008) já discutiu em revisão sobre a colaboração entre professores: o trabalho colaborativo auxilia no enfrentamento dos desafios vividos na escola e cria um ambiente rico em aprendizagens capaz de proporcionar um maior de grau de satisfação profissional marcado por valores como o compartilhamento e a solidariedade. De fato, quando se discute com um colega sobre possibilidades, desafios e experiências vivenciadas, há a abertura para o enriquecimento das maneiras de pensar, agir e resolver problemas, facilitando o surgimento de soluções, ideias e sucesso perante a já difícil tarefa de ensinar, que se tornou ainda mais complexa no contexto de pandemia.

Outra professora também destaca a questão da colaboração nesse período: "O trabalho em equipe foi fundamental para que pudéssemos suportar a pressão de todos os lados" (Julia). $\mathrm{O}$ apoio e incentivo dos pares para enfrentar as dificuldades do período são também caracterizados por Maria e Bianca:

Como eu iria ficar atrás de uma tela e passar o conteúdo? E para chamar a atenção da criança perante aos pais? Como prender a atenção dentro do ambiente deles, competindo com muitos outros estímulos? Foram inúmeras perguntas sem respostas e a única certeza é que eu teria que me reinventar e me desdobrar para conseguir passar por esse período turbulento. E a sorte era que tínhamos uma equipe que sempre acreditou que seria possível e o tempo todo nos encorajava dizendo que estávamos realizando muito além da expectativa da escola e dos pais (Maria).

Quando nos vimos diante de um tablet/computador, foi muito difícil para nos conectarmos com eles. A professora da sala teve que se reinventar. Fazer algo para chamar eles para ela, para que toda semana eles voltassem. Nossa equipe conseguiu! (Bianca).

As expectativas de apoio de Ana, Júlia, Maria e Bianca, entre outras, são convergentes com experiências de colaboração vividas por professoras de outras escolas e contextos. Almeida e Dalben (2020), por exemplo, acompanharam reuniões de planejamento de professores do 
estado do Paraná, observando uma rede de ajuda apelidada de "quem sabe mais ajuda quem sabe menos". Com as dificuldades de uso das ferramentas digitais por parte de alguns professores instaurou-se um movimento de acolhimento e reflexão sobre a implicação pedagógica das ações propostas. Investiram, em conjunto, na manutenção do entusiasmo da equipe, na garantia do conhecimento minimamente necessário dos recursos digitais e na reflexão sobre a qualidade das atividades em meio digital.

Nóvoa (2020) destaca que nos tempos difíceis da pandemia foram as professoras, em colaboração umas com as outras e com as famílias, que conseguiram produzir as melhores respostas para organizar estratégias pedagógicas significativas. Segundo o autor, a colaboração foi o elemento decisivo para impulsionar as professoras na direção do bem comum.

\subsection{Formação continuada no contexto da escola}

Se a reflexão e a revisão da própria prática, assim como o trabalho colaborativo, se mostram como possíveis lições aprendidas com a docência no ensino remoto emergencial, uma terceira e importante dimensão é evidenciada nas narrativas docentes. As professoras participantes da pesquisa anunciam que, diante dos desafios impostos pelo ensino remoto, compreenderam melhor a importância da formação continuada oferecida no contexto da escola. Essa perspectiva de formação centrada nas situações de trabalho corresponde à ideia de formação como socialização profissional, isto é, baseada na complexidade da ação docente como referência para a reflexão e para a sistematização dos saberes construídos no contexto da escola (CANÁRIO, 2000).

Sara, Isis e Carla reforçam a importância de a escola assumir a formação continuada como dispositivo para o enfrentamento das necessidades das professoras:

Pude perceber também a necessidade de formação continuada, o quanto nós precisamos estar atentos ao momento, nos desapegar ainda mais das ideias que trazemos enraizadas em nossa atuação como docentes e de como a escola deve ser e nos capacitarmos em torno de novas tecnologias e modalidades de ensino (Sara).

Apesar da minha escola se preocupar bastante com a formação contínua das professoras, eu não tenho treinamentos específicos para as aulas [remotas], então eu mesma busco artigos na internet, cursos e grupos de discussão e trocas de experiências (Isis).

Acho interessante se houvesse mais workshops ou treinamentos para se familiarizar com as diferentes plataformas digitais e recursos online que existem atualmente. Gostaria de ver algum programa ou treinamento para alinhar ou compartilhar métodos de avaliação que gerem relatórios mais precisos sobre o aprendizado dos alunos (Carla).

As narrativas apontam que, muitas vezes, a formação continuada que pode acontecer fora da escola é tida como a solução para as dúvidas e angústias dos docentes perante seus desafios diários e, especialmente, na situação de crise que passaram em 2020 e que perdura até o momento da escrita deste texto. Porém, é na experiência, no fazer diário, na troca entre seus pares que os sujeitos se reconhecem e, com sua subjetividade, constroem saberes. É importante que haja espaço na escola para o diálogo entre teoria e prática, entre o que se aprende no dia a dia do fazer pedagógico e os conhecimentos teóricos. A formação é um processo contínuo que se constrói e desconstrói a cada nova discussão e reflexão. 
Esta perspectiva é coerente com os princípios defendidos por Sadalla e Sá-Chaves (2008) para quem o ambiente formativo que favorece o desenvolvimento profissional implica, além de oportunidades de interagir com os outros e sentir-se apoiado, refletir sobre e para a prática com base na discussão crítica das teorias.

O que se constata a partir das narrativas é que durante o período de aulas remotas, a formação do dia a dia, mais subjetiva e referente à prática cotidiana foi alterada, mas não totalmente suprimida do fazer pedagógico. Este modo de formação se realiza com a troca entre professoras, com discussões entre colegas que se ajudaram a fim de sobreviverem a tantas mudanças. No entanto, parece que a formação relativa aos conhecimentos teóricos ficou em segundo plano, talvez devido à urgência da situação.

Neste sentido, as narrativas retratam certa compreensão, já instituída no ambiente escolar, de que a formação profissional docente se configura como uma dimensão acessória. Muito embora se reconheça sua importância e validade para a construção da identidade docente, diante das urgências do cotidiano o tempo de estudo, apropriação teórica e reflexão sobre a própria prática é subtraído, em nome da priorização de outras atividades formativas mais pontuais e técnicas, como se diante de situações limítrofes, como a atualmente vivenciada, fosse mais útil obter respostas prontas a buscar, nos sistemas teóricos formas de compreender a realidade e de pensar alternativas para as dificuldades encontradas.

No trecho a seguir, Angela reflete sobre as habilidades formativas que ela desenvolveu durante esse período, chamando a atenção para a necessidade de uma formação voltada para o preparo emocional para lidar com as situações difíceis da pandemia.

\begin{abstract}
Descobri que mesmo com tudo que sabia de tecnologia, ainda era pouco, e apesar de toda dificuldade que este ano trouxe, tive a oportunidade de crescer como educadora e como pessoa. Desenvolvi novas habilidades tecnológicas, habilidades de relacionamento e também a paciência para passar pelos dias em que não foi possível me relacionar, a não ser virtualmente [...]. Vejo como necessidade formativa um preparo emocional para situações que não esperamos; e também um preparo para reorganizarmos e, quando necessário, "improvisarmos" planejamentos, atividades e afins na instituição escolar (Angela).
\end{abstract}

A professora atenta para a importância de a formação docente ser minimamente coerente e ser organizada de modo a contemplar afeto, movimento e cognição, uma vez que é isso o que se defende também como ideal no trabalho a ser desenvolvido com os alunos. Novamente é destacada a atenção dada, no contexto da pandemia, para iniciativas formativas aligeiradas e prescritivas que possivelmente trouxeram alguns esclarecimentos pontuais e auxiliaram na melhor familiaridade com os recursos técnicos de interação virtual, mas que em nada aproximam a professora da construção de conhecimento e na elaboração sensível daquilo que é vivido. Por isso, apesar da imersão em cursos, palestras, lives e podcasts, o sentimento é de não dar conta e de ainda ter muito a buscar e aprender.

Este sentimento ainda é somado à falta de participação e voz ativa nos momentos de decisão, dentro do grupo pedagógico da instituição, sobre como conduzir e planejar as estratégias de formação da equipe docente, o que é registrado por Larissa:

Senti falta de participação da equipe docente nas discussões para tomada de decisões sobre os inúmeros modelos que adotamos ao longo do ano, pois fomos nós, 
professoras e alunos/famílias, os mais impactados por todas as mudanças. Muitas vezes tivemos que fazer tudo às pressas (Larissa).

A professora lembra da importância da construção coletiva do trabalho e da formação em contexto que supõe diálogo, negociação de expectativas, troca de saberes e decisões colegiadas. Se em outros momentos a participação ativa e a instituição de coletivos já era defendida, neste momento a articulação e fortalecimento de tais práticas se faz imprescindível.

Neste sentido, a própria escrita narrativa, possibilitada às professoras como maneira de estreitar vínculos, manter o diálogo e refletir sistematicamente sobre o trabalho pedagógico, se configura como potente estratégia formativa, assim como apresentado por Ferreira, Prezotto e Terra (2020, p. 1667): "o contexto atual de isolamento social nos leva a pensar a prática narrativa pedagógica como forma de insistência no diálogo e na constituição de coletivos que se apoiem e se suportem mesmo à distância, em outras novas circularidades". A formação profissional docente está presente, na escrita das professoras, como estratégia de aprimoramento pessoal que as municia e repertoria para uma atuação mais orientada e crítica diante do cenário de incerteza vivido. Ao mesmo tempo, é pela formação continuada que a docência se reafirma como espaço criativo e autoral, que alia sincronicamente o pensar, o fazer e o sentir.

\section{Considerações finais}

Foram diversas as questões apresentadas pelas professoras em suas narrativas e, sem resposta única, o que elas expressam é que o momento vivenciado é de grande tensão e insegurança. Vendo-se exigidas além de suas capacidades e no limite de suas condições, registram ter encontrado algumas respostas na formação técnica, porém estas são insuficientes para dar conta de toda a complexidade do ensino remoto emergencial. Assim, a parceria com os demais colegas de profissão, o trabalho em grupo, o diálogo, a inteligência emocional, a sensibilidade e o acolhimento foram algumas das possibilidades de enfrentamento e resistência às dificuldades, ou os caminhos para encontrar respostas para tantas dúvidas.

\footnotetext{
Com o passar do tempo ficou cada vez mais perceptível de que dá para estar perto, mesmo estando longe. Dá para dar carinho, abraçar e se sentir abraçado mesmo com uma tela separando a gente dos alunos. Descobrir estratégias que faziam parte da rotina presencial e que pudessem ser adaptadas para o online. Descobri que dá para fazer uma aula divertida e dinâmica sem precisar sair do lugar. Descobri que os alunos são muito mais capazes, responsáveis, compreensivos, esforçados e resilientes do que a gente pensa que eles são (Branca).
}

Narrativas como a de Branca demonstram o sentimento de gratidão e de aprendizagem por parte das professoras quando verificam que foi possível realizar o ensino, mesmo diante de diferentes circunstâncias. A partir de seus registros, é possível compreender que no ensino remoto emergencial, independente da modalidade de atividades propostas, nos melhores cenários apresentados pelas professoras, consegue-se assegurar alguma possibilidade de ensino e comunicação, mas não necessariamente de educação e diálogo.

Num cenário de provisoriedade que já se estende ao segundo ano, acentua-se a característica de bombeiro do trabalho docente, deslocando sua atenção às urgências e emergências. O trabalho central, que é o de organização do trabalho pedagógico e de formação, 
fica por vezes em segundo plano. No entanto, as docentes narram lições importantes deste período atravessado e demonstram maior propriedade e segurança em suas conduções com o passar do tempo, sendo capazes de certo distanciamento e análise daquilo que é vivenciado. Em suas palavras são percebidos aprendizados efetivos que podem auxiliar tanto na maneira como as professoras se compreendem neste período pandêmico, quanto na docência futura, em novos/outros contextos.

\section{Referências}

ALMEIDA, Luana Costa.; DALBEN, Adilson. (Re)organizar o trabalho pedagógico em tempos de COVID-19: no limiar do (im)possível. Educação e Sociedade, São Paulo, v. 41, p. 1-20. 2020. Disponível em:

https://www.scielo.br/j/es/a/sJBDsSZGLL9kt4b8YMB8wRN/?lang=pt. Acesso em: 10 abr. 2021.

BARBOSA, Andreza; CUNHA, Renata Cristina Oliveira Barrichelo; MARTINS, Verônica. Estado do conhecimento sobre jornada de trabalho docente no ensino fundamental e médio. Horizontes, Itatiba, v. 37, p. 1-27. 2019. Disponível em:

https://revistahorizontes.usf.edu.br/horizontes/article/view/578. Acesso em: 10 abr. 2021.

CANÁRIO, Rui. Formação profissional: problemas e perspectivas de futuro. Forum, Braga, v. 27, p. 125-139, jan./jun. 2000. Disponível em:

https://revistas.uminho.pt/index.php/forum/article/download/2845/2806. Acesso em: 8 mar. 2021.

CUNHA, Renata Cristina Oliveira Barrichelo; PRADO, Guilherme do Val Toledo. Formação centrada na escola, desenvolvimento pessoal e profissional de professores. Revista de Educação PUC-Campinas, Campinas, v. 28, p. 103-113, jan./jun. 2020. Disponível em: https://periodicos.puc-campinas.edu.br/seer/index.php/reveducacao/article/view/79. Acesso em: 25 jun. 2021.

CUNHA, Renata Cristina Oliveira Barrichelo; OMETTO, Cláudia Beatriz de Castro Nascimento; PRADO, Guilherme do Val Toledo. Trabalho docente coletivo e coordenação pedagógica: entre a heterogeneidade do cotidiano e um projeto de formação de professores.

Revista de Educação PUC-Campinas, Campinas, v. 18, n. 2, p. 171-179, maio/ago. 2013. Disponível em: https://periodicos.puccampinas.edu.br/seer/index.php/reveducacao/article/view/2026. Acesso em: 25 jun. 2021.

DAMIANI, Magda Floriana. Entendendo o trabalho colaborativo em educação e revelando seus benefícios. Educar em Revista, Curitiba, v. 31, p. 213-230, 2008. Disponível em: https://www.scielo.br/j/er/a/FjYPg5gFXSffFxr4BXvLvyx/?format=pdf\&lang=pt. Acesso em: 25 jun. 2021.

DIAS, Erika; PINTO, Fátima Cunha Ferreira. A Educação e a Covid-19. Ensaio: Avaliação e Políticas Públicas em Educação, Rio de Janeiro, v. 28, n. 108, p. 545-554, jul./set. 2020. Disponível em: https://www.scielo.br/j/ensaio/a/mjDxhf8YGdk84VfPmRSxzcn/?lang=pt. Acesso em: 10 abr. 2021.

FELTRIN, Tascieli; BATISTA, Natália Lampert. Autoformação docente em tempos de pandemia: da (im)possibilidade da reinvenção sem cuidado de si. Revista Científica 
Educ@ção, Miracatu, v. 8, p. 1017-1029, out. 2020. Disponível em: https://periodicosrefoc.com.br/jornal/index.php/RCE/article/view/128. Acesso em: 10 abr. 2021.

FERREIRA, Luciana Haddad; BARBOSA, Andreza. Lições de quarentena: limites e possibilidades da atuação docente em época de isolamento social. Práxis Educativa, Ponta Grossa, v. 15, p. 1-24, 2020. Disponível em: https://www.revistas2.uepg.br/ index.php/praxiseducativa. Acesso em 21 jul. 2020.

FERREIRA, Luciana Haddad; PREZOTTO, Marissol; TERRA, Juliana. Confiar. Con.fiar. Confi(n)ar: a narrativa como estratégia formativa ante às recentes transformações sociais. Revista Brasileira de Pesquisa (Auto)biográfica, Salvador, v. 5, n. 16, p. 1664-168, 2000. Disponível em: https://www.revistas.uneb.br/index.php/rbpab/article/view/9196/7327. Acesso em: 10 abr. 2021.

FREITAS, Maria Teresa Menezes; FIORENTINI, Dario. As possibilidades formativas e investigativas da narrativa em educação matemática. Horizontes, Itatiba, v. 25, n. 1, p. 63-71, 2007. Disponível em:

http://lyceumonline.usf.edu.br/webp/portalUSF/itatiba/mestrado/educacao/uploadAddress/Ho rizontes_25_1_06[11067].pdf. Acesso em: 13 abr. 2021.

FULLAN, Michael; HARGREAVES, Andy. 2001. Por que é que vale a pena lutar? O trabalho de equipa na escola. Porto: Porto, 2001.

GALVÃO, Cecília. Narrativas em educação. Ciência \& Educação, Bauru, v. 11, n. 2, p. $327-$ 345, 2005. Disponível em:

https://www.scielo.br/j/ciedu/a/H5hSMRYMyjhYtBxqnMVZVJH/?lang=pt\&format=pdf. Acesso em: 10 abr. 2021.

GOMES, Romeu. A análise de dados em pesquisa qualitativa. In: MINAYO, Maria Cecília de Souza. Pesquisa social: teoria, método e criatividade. Petrópolis: Vozes, 1993. p. 67-80.

LIMA, Maria Emília Caixeta de Castro; GERALDI, Corinta Maria Grisólia.; GERALDI, João Wanderley. O trabalho com narrativas na investigação em educação. Educação em Revista, Belo Horizonte, v. 31, n. 1, p. 17-44, jan./jun. 2015. Disponível em:

https://www.scielo.br/j/edur/a/w7DhWzM5mB4mZWLB5hthLVS/abstract/?lang=pt. Acesso em: 13 abr. 2021.

MACEDO, Renata Mourão. Direito ou privilégio? Desigualdades digitais, pandemia e os desafios de uma escola pública. Estudos Históricos, Rio de Janeiro, v. 34, n. 73, p. 262-280, maio/ago. 2021. Disponível em:

https://www.scielo.br/j/eh/a/SGqJ6b5C4m44vh8R5hPV78m/?lang=pt\&format=pdf. Acesso em: 10 abr. 2021.

MARTINS, Vivian; CASTRO, Bárbara Rodrigues; TRANCOSO, Michelle Viana. Criações e percepções docentes no ensino remoto durante a pandemia de Covid-19: uma pesquisa com os cotidianos. Revista Artes de Educar, Rio de Janeiro, v. 6, p. 157-182, jun./out. 2020.

Disponível em: https://www.e-publicacoes.uerj.br/index.php/riae/article/view/51922/35495.

Acesso em: 10 abr. 2021. 
MINAYO, Maria Cecília de Souza. Pesquisa social: teoria, método e criatividade. Petrópolis: Vozes, 1993.

NÓVOA, Antonio. A pandemia de Covid-19 e o futuro da Educação. Revista Com Censo, Brasília, v. 7, n. 3, p. 8-12, 2020. Disponível em:

http://periodicos.se.df.gov.br/index.php/comcenso/article/view/905. Acesso em: 10 abr. 2021.

PERES, Maria Regina. Novos desafios da gestão escolar e de sala de aula em tempos de pandemia. Revista Administração Educacional, Recife, v. 11, n. 1, p. 20-31, 2020.

Disponível em: https://periodicos.ufpe.br/revistas/ADED/article/view/246089. Acesso em: 10 abr. 2021.

RONDINI, Carina Alexandra; PEDRO, Ketilin Mayra; DUARTE, Cláudia dos Santos. Pandemia da COVID-19 e o ensino remoto emergencial: mudanças na prática pedagógica. Interfaces Científicas, Aracajú, v. 10, n. 1, p. 41-57, 2020. Disponível em: https://periodicos.set.edu.br/educacao/article/view/9085/4128. Acesso em: 10 abr. 2021.

SADALLA, Ana Maria Falcão de Aragão; SÁ-CHAVES, Idália da Silva Carvalho. Constituição da reflexividade docente: indícios de desenvolvimento profissional coletivo. ETD - Educação Temática Digital, Campinas, v. 9, n. 2, p. 189-203, 2008. Disponível em: https://periodicos.sbu.unicamp.br/ojs/index.php/etd/article/view/826. Acesso em: 8 abr. 2021.

SALDANHA, Luís Carlos Dallier. O discurso do ensino remoto durante a pandemia de COVID-19. Revista Educação e Cultura Contemporânea, Rio de Janeiro, v. 17, n. 50, p. 124-144, 2020 Disponível em:

https://www.researchgate.net/publication/349009128_O_discurso_do_ensino_remoto_durante _a_pandemia_de_COVID-19. Acesso em: 5 maio 2021.

SANTOS, Euzanir; LIMA, Idelsuite de Sousa; SOUSA, Nádia Jane. "Da noite para o dia" o ensino remoto: (re)invenções de professores durante a pandemia. Revista Brasileira de Pesquisa (Auto)Biográfica, Salvador, v. 5, n. 16, p. 1632-1648, 2020. Disponível em: https://redib.org/Record/oai_articulo3019092-\%E2\%80\%9Cda-noite-para-odia\%E2\% 80\%9D-o-ensino-remoto-reinven\%C3\% A7\%C3\%B5es-de-professores-durante-apandemia. Acesso em: 10 abr. 2021.

SILVA, Ivandison Miranda. O governo Bolsonaro, a crise política e as narrativas sobre a pandemia. Revista Brasileira de Pesquisa (Auto)biográfica, Salvador, v. 5, n. 16, p. 14781488, 29 dez. 2020. Disponível em: https://revistas.uneb.br/index.php/rbpab/article/view/9227. Acesso em: 27 ago. 2021.

VERDASCA, José. Pandemia: narrativas de professores. Saber \& Educar, Porto, v. 29, p. 112, 2021. Disponível em: http://revista.esepf.pt/index.php/sabereducar/article/view/403/451. Acesso em: 10 abr. 2021.

VIEIRA, Lívia Maria Fraga; FALCIANO, Bruno Tovar. Docência na educação infantil durante a pandemia: percepções de professoras e professores. Revista Retratos da Escola, Brasília, v. 14, n. 30, p. 788-805, 2020. Disponível em: http://retratosdaescola.emnuvens.com.br/rde/article/view/1224. Acesso em: 10 abr. 2021.

WEYH, Laís Francine; NEHRING, Cátia Maria. O reflexo da pandemia na educação escolar e no trabalho docente. JORNADA DE PESQUISA, 25, 2020, Unijuí. Salão do 
Conhecimento. Unijuí: Unijuí. p. 1-11. Disponível em:

https://publicacoeseventos.unijui.edu.br/index.php/salaoconhecimento/article/view/18472. Acesso em: 10 abr. 2021.

Recebido em setembro de 2021.

Aprovado em outubro de 2021. 